Dialectologia 25 (2020), 1-24.

ISSN: 2013-2247

Received 24 April 2018.

Accepted 26 August 2018.

\title{
CONSTRUCCIONES POSESIVAS EN EL ARAGONÉS CENTRAL Y MERIDIONAL A FINALES DE LA EDAD MEDIA
}

\author{
Elena AlBesA Pedrola \\ Universidad de Zaragoza * \\ ealbesa@unizar.es
}

\section{Resumen}

Este estudio pretende analizar en profundidad la expresión de la posesión en documentación notarial procedente del centro y sur de Aragón durante el siglo xV, con especial atención a la construcción (artículo) + sustantivo + posesivo tónico (la casa mía), cuyo origen y amplia difusión sitúan algunos autores en la región aragonesa, y a posesivo átono + sustantivo (mi casa), que ya es la forma más habitual en estas mismas fechas en el castellano. Comprobaremos si los resultados obtenidos en dicho análisis muestran alguna diferencia con el castellano y con documentación procedente del norte de Aragón, puesto que la variación interna dentro del aragonés medieval en otros aspectos morfosintácticos es notable. Para ello, recabamos información de seis documentos notariales: tres zaragozanos y tres turolenses. Cada uno de ellos abarca un periodo de tiempo limitado, si bien siempre enmarcados dentro del siglo xv, que es un siglo de alta importancia para el aragonés medieval puesto que es en esta centuria cuando se acelera y culmina la castellanización de la mayor parte de Aragón.

\section{Palabras clave}

construcciones de posesivo, aragonés medieval, siglo xv, documentación notarial, variación interna

\footnotetext{
* Departamento de Lingüística y Literaturas Hispánicas. Área de Lengua Española. Despacho 416. C/ Pedro Cerbuna, 12, 50009 Zaragoza.
} 


\title{
POSSESSIVE CONSTRUCTIONS IN ARAGONESE TEXTS FROM THE CENTRE AND SOUTH OF ARAGÓN
}

\section{AT THE END OF THE MIDDLE AGES}

\begin{abstract}
The aim of this work is to deeply analyze how possession is revealed in notarial documents written in the center and the south part of Aragón in the 15th century. Special attention will be paid to this construction: (article) + noun + possessive pronoun (la casa mía), as its origin and expansion is located in Aragón; and also to this one: possessive adjective + noun (mi casa), as it is the common structure in Castilian by the same period of time. We will check if there is a difference between the results obtained in our analysis and what happened in Castilian at the same time, due to well-known variation in Aragonese among other morphological aspects. In order to get accurate data, we will extract information from 3 notarial documents from Zaragoza and another 3 documents from Teruel. All of them were handwritten in the 15 th century, which is a relevant age in the history of Aragonese language because it is considered the period of the definitive advance of Castilian in Aragón and the loss of the traditional romance in the great part of the kingdom.
\end{abstract}

\section{Keywords}

possessive constructions, medieval Aragonese, 15th century, notarial documents, inner variation

\section{Introducción}

La manera por la que las distintas lenguas romances han optado para expresar la posesión ha llamado la atención de los investigadores en las últimas décadas. Claro ejemplo de ello es la gran cantidad de bibliografía que se ha escrito, por ejemplo, con referencia al castellano y sus variedades tanto dentro de la Península como fuera de ella, bien en la sincronía bien en la diacronía. De este modo, contamos con verdaderos estudios canónicos que, desde una perspectiva diacrónica -que es la que nuestro trabajo comprende- han marcado un inicio para estudios posteriores, así el de Lapesa (2000), el de Clavería (1992), el de Eberenz (2000) o los de Company (2001, 2006, 2009), entre otros. Por supuesto, abundan también aquellos estudios que han focalizado su atención en variedades del castellano o en otras lenguas romances peninsulares, como las hablas 
norteñas (Pato 2015), el castellano del País Vasco (Gómez Seibane 2010) y el de León (Egido 1999) o el catalán (Pérez Saldanya 2009). ${ }^{1}$

Nuestro trabajo también se enmarca dentro de este interés diacrónico por una variedad romance peninsular como es el aragonés medieval, en concreto, el aragonés propio de una tradición notarial escrito en el centro y sur de Aragón en el siglo xv. Debemos recordar, en este momento de la investigación, que el aragonés medieval se caracteriza por su falta de homogeneidad en todo el reino de Aragón, más todavía si tenemos en cuenta las diferencias que pudo haber entre el aragonés propio de los valles pirenaicos y el aragonés modificado por un proceso de nivelación en su expansión hacia el sur durante la Reconquista y la consecuente repoblación de las tierras meridionales con gentes venidas de diversos territorios peninsulares, y aún extra peninsulares. Además, en el siglo XV se acelera y culmina la castellanización de la mayor parte del territorio aragonés, es decir, de todo el Reino a excepción de los mencionados valles pirenaicos, que conservan su lengua, en mayor o menor medida, hasta la actualidad.

El principal objetivo de este estudio es, pues, analizar qué mecanismos emplea preferentemente este aragonés meridional para expresar la posesión y si estos se diferencian de los que habitualmente usa el castellano o los que selecciona el aragonés del Alto Aragón. Asimismo, queremos comprobar si existe variación interna en estos recursos dentro del mismo corpus seleccionado $y$, si así es, a qué motivos puede responder.

No partimos, para ello, desde cero, pues son varios los estudios que se han realizado en torno a la posesión en territorio aragonés. De este modo, en época contemporánea, autores como Badia (1950: 115-116) en el valle de Bielsa, Kuhn (2008 [1935]: 133) en el valle de Echo y Haensch (1961-1962: 137-138) en la Alta Ribagorza han llamado la atención sobre la utilización de la construcción artículo + posesivo tónico + sustantivo (el suyo mocé). Esta construcción es señalada para la época medieval por Alvar (1953: 285-286) y Romero Cambrón (2014: 356). Podemos adelantar que esta construcción parece ser más propia de las hablas norteñas que de las del centro y sur

\footnotetext{
${ }^{1}$ Aparte deben mencionarse los estudios que se han hecho -y que se siguen haciendo- sobre las distintas variedades del español hablado en Latinoamérica, que han despertado un interés creciente en los últimos años.
} 
aragonés. Además, debemos destacar otra construcción que, en los últimos años, ha merecido la atención de Romero Cambrón $(2014,2016)$, cuyo origen y amplia difusión sitúa esta autora en la región aragonesa: (artículo) + sustantivo + posesivo tónico ("Johan Ximenez, marido suyo"; "lexo el manto cardeno mio"). Comprobaremos en este análisis su (in)existencia dentro de la documentación aragonesa seleccionada.

Por supuesto, y como hemos mencionado con anterioridad, los estudios sobre el castellano medieval son ciertamente abundantes. Entre ellos destacan aquellos que se han centrado en la expresión de la posesión constituida por artículo + posesivo átono + sustantivo (la mi casa). El interés de esta construcción reside en su pugna y posterior pérdida frente a la forma que se ha considerado en ocasiones "no marcada": posesivo + sustantivo (mi casa). Dicha pugna se entiende desde la hipótesis de que ambas poseen e identifican características diferentes dentro de la expresión de la posesión. Varios autores como Lapesa (2000), Clavería (1992) y Eberenz (2000), entre otros, han afirmado que el uso de artículo + posesivo átono + sustantivo obedece a factores enfáticos, expresivos, retóricos o realzadores de la posesión; Company (2001: 85) entiende que "es su carácter muy marcado y especializado el que motiva un comportamiento gramatical huidizo y las hace formas ideales para explotación estilística". Por su parte, Serradilla (2003: 267) expone que esta construcción sirve, en las zonas en las que se ha mantenido, para destacar la unicidad, es decir, para resaltar lo único, de ahí que predomine su uso en singular. En cuanto a factores gramaticales, Rodríguez Barreiro (2003: 289) parece distinguir algunas características, como la modalidad de posesión expresada por el sustantivo, los rasgos de subcategorización del sustantivo o la función sintáctica de la frase que introduce, que orientan la ausencia / presencia del artículo, aunque no la determinan en ningún momento.

Por otra parte, la cronología para el abandono del grupo artículo + posesivo átono + sustantivo en el castellano suele situarse a mediados del siglo xv. De este modo, casi la totalidad de estudiosos que han investigado sobre este tema, localizan una decadencia de esta construcción en el siglo XIV, que se acentúa en el XV, y un abandono casi definitivo por parte de la lengua estándar en el XVI (Lapesa 2000: 430; Eberenz 2000: 265-266; Serradilla 2003: 260-261; Company 2009: 788); si bien Clavería (1992: 357) declara que, en documentación notarial, el porcentaje de las formas con artículo aumenta un poco en el 
siglo XV con respecto al XIV. A pesar de estos datos, Serradilla (2003: 261) afirma que esta fórmula se mantuvo durante más tiempo en aragonés que en el castellano.

Con el fin de determinar qué estructuras posesivas son de uso preferente en el centro y sur de Aragón, hemos elegido seis documentos redactados en diversas partes de las actuales provincias de Zaragoza y de Teruel. Todos ellos datan del siglo xV y, debido al proceso de castellanización y a la variación interna del aragonés medieval, contienen rasgos lingüísticos específicos de dicha lengua en diversa proporción; de hecho, en algunos casos todavía puede hablarse de un completo mantenimiento de la lengua autóctona con rasgos de castellanización, mientras que en otros es preferible hablar ya de una avanzada castellanización, si bien sembrada de aragonesismos. De dichos seis documentos hemos extraído las fórmulas lingüísticas que expresan posesión que contienen, al menos, un posesivo y un sustantivo; es decir, hemos omitido las construcciones en las que no se nombra directamente lo poseído (el mío), en las que el propio artículo contiene características posesivas (“levantó la mano”) y las de genitivo simple ("la casa de él"); sin embargo, hemos anotado, cuando así lo mostraban los textos, la doble posesión con un genitivo (su casa de él). Estos extractos nos servirán para obtener datos concretos y mesurables que puedan ser contrastados con los que ofrecen otros estudios.

\section{Corpus seleccionado}

Como ya hemos anotado, seis son los documentos que sirven de base para este estudio: tres se sitúan en la provincia de Zaragoza, mientras que los otros tres son turolenses. Pasamos a anotar algunas de las características más importantes de cada uno de ellos.

Los pergaminos aragoneses del Fondo Sástago (Lleal Galcerán et al. 2007) son una colección de documentos conservados en el Archivo de la Corona de Aragón (Barcelona) procedentes del archivo familiar de los condes de Sástago, del linaje de los Alagón. Son, todos ellos, textos notariales relacionados con las propiedades de los condes de Sástago o 
sus familiares. De los 77 pergaminos de los que consta este gran volumen, hemos seleccionado ocho (33- 40) que datan entre 1449 y 1452. La extensión de cada uno de los documentos es variable, teniendo, por ejemplo, 36 líneas el $n .036$, mientras que el $n .035$ tiene 268; además, la longitud de cada línea también cambia de un documento a otro. ${ }^{2}$ En líneas generales, hemos advertido que estos textos conservan de manera precisa el antiguo romance aragonés, si bien, como es lógico, también se aprecian algunos rasgos lingüísticos castellanos en alguno de ellos.

Los documentos de Vicente Rodilla, notario de Zaragoza (del Campo 2011), son un compendio de testamentos fechados entre 1384 y 1407. De dicho Libro de Testamentos hemos seleccionado seis documentos: uno de 1400 (1v.-4r.) y cinco de 1403 (49r.-61r), es decir 16 folios rectos y vueltos. Estos textos, debido quizá a su temprana fecha de redacción en comparación con el resto, también muestran una visible impronta aragonesa.

El siguiente bloque de análisis corresponde a los protocolos notariales de Bartolomé Roca y de otros notarios zaragozanos de mediados del siglo XV (Lozano Gracia 2012). Concretamente hemos escogido 36 folios rectos y vueltos de Bartolomé Roca fechados en 1462 y los 14 documentos que se adjuntan al final del volumen y que pertenecen a otros notarios diversos, redactados entre 1443 y 1477. Todos ellos se conservan en el Archivo Histórico Provincial de Zaragoza y, si bien sus características lingüísticas son variables, presentan más rasgos lingüísticos castellanos que sus coterráneos de Vicente Rodilla.

Ya en la provincia de Teruel, contamos con los protocolos notariales de Joan de Morales (París Marqués 2016), notario de Samper de Calanda, localidad situada en la comarca del Bajo Aragón histórico, cerca de la frontera con la provincia de Zaragoza. De los casi 300 registros de protocolo que componen este libro, hemos elegido 80 de ellos, que abarcan los años 1499 y 1500. Por la fecha de redacción más tardía que el resto y, quizá, por su situación geográfica, estos documentos están notablemente más castellanizados que los demás que hemos analizado.

También en el Bajo Aragón histórico, pero más cerca de la frontera con Cataluña, está Alcañiz, localidad de la que proviene el notario Salvador de Aguas, redactor único de

\footnotetext{
${ }^{2}$ Al ser pergaminos, no es posible contabilizar los fragmentos seleccionados para el estudio en folios, como suele ser habitual.
} 
otro bloque de protocolos (Albesa en prensa). Son, en total, 51 folios rectos y vueltos no consecutivos redactados entre 1450 y 1453 . Conservan de manera notable los rasgos del antiguo romance autóctono y también contienen algunas peculiaridades lingüísticas catalanas debido a la cercanía con el territorio catalanohablante.

Por último, hemos escogido 60 documentos (del 30 al 90) de los 120 que componen el estudio de Terrado (1991). Se localizan en Teruel capital y alrededores y fueron redactados entre 1420 y 1453. La extensión de cada uno de ellos no es estable, pudiendo encontrar, por ejemplo, unos textos de dos folios rectos y vueltos y otros de doce. La lengua de redacción se muestra bastante castellanizada, si bien todavía se encuentran huellas lingüísticas visibles del aragonés un día hablado en esta región. Aún con todo, debemos tener en cuenta que ya el Fuero de Teruel (siglo XIII) muestra características lingüísticas ajenas al aragonés y más propias de Castilla por su situación geográfica.

Consideramos, pues, que esta selección abarca en su totalidad el centro y el sur de Aragón, un espacio amplio, pero bien delimitado; además, cubre el periodo de tiempo fijado, el siglo xv, que fue decisivo para la evolución de la lengua en esta región. ${ }^{3}$

\section{Extracción de datos}

\subsection{Los pergaminos aragoneses del Fondo Sástago}

Los pergaminos del Fondo Sástago analizados contienen un total de 109 construcciones de posesivo, de las cuales:

- Posesivo átono + sustantivo son 44 casos (40,36\%): "de tod nuestro dreyto", "sian sacados de dentro de mjs casas", "nuestras continuas habitaciones", "todos nuestros

\footnotetext{
${ }^{3}$ Somos conscientes de la diferencia de folios y documentos analizados en cada uno de los bloques. Esto solamente responde a las características de las propias obras seleccionadas y, sobre todo, al número de expresiones posesivas que se dan en cada una de ellas. Es decir, hemos querido obtener una muestra significativa, por lo que, si en algunos textos aparecían escasas construcciones de posesivo, creímos necesario examinar más folios del mismo documento, mientras que, si un menor número de folios exhibía una cantidad adecuada de estas construcciones, no era necesario examinar más.
} 
bienes", "a mjs propias mjsiones et expensas", "al dito don Gaspar Royz et sus herederos", "en ayuda de su matrimonio".

- (Artículo) + sustantivo + posesivo tónico son 59 casos (54,12\%): "o las succesores nuestras", "en nombre nuestro proprio", "por toda la tierra et Senyoria suya", "e de bienes nuestros e suyos", "por algunas de las sobreditas jndempnidades vuestras", "hunas casas mjas", "en poder mjo", "Beatriz Royz filla suya".

- Artículo + posesivo átono + sustantivo son 5 casos (4,58\%): "en el dito su vitimo testament", "por la dita su muller", "en ayuda del dito su matrimonio", "de los ditos su padre et madre", "en ayuda del dito su matrimonio").

- Artículo + posesivo tónico + sustantivo solamente 1 caso (0,91\%): “cadaunas cosas dessus ditas hauer por firmes e seguras por mj e los mjos herederos e successores".

De estos porcentajes podemos extraer varias ideas. En primer lugar, la construcción preferida en estos documentos es (artículo) + sustantivo + posesivo tónico, construcción que, como anotamos anteriormente, Romero Cambrón $(2014,2016)$ indica que podría ser de preferencia aragonesa; sin embargo, la estructura habitual en castellano ya en el siglo $\mathrm{XV}$, posesivo átono + sustantivo también es muy frecuente. No obstante, desde un punto de vista cualitativo, la primera expresión resulta mucho más interesante, puesto que posesivo átono + sustantivo tiende a aparecer, en estos pergaminos, en fórmulas fijas propias del lenguaje notarial o en construcciones que se repiten habitualmente ("nuestra sciencia", "renuncio a mi judge", "de mi dreito"). Aún con todo, hay sustantivos o expresiones que aparecen indistintamente con diferentes estructuras posesivas: "en poder mjo" / "en mj poder"; "en las casas de nuestras habitaciones e suyas", "nuestras continuas habitaciones" / "dentro de las casas de la habitación vuestra"; "a expensas mjas", "a todo Risch periglo fortuna danyo mjsiones et expensas nuestras" / "a mjs propias mjsiones et expensas"; "en nuestros nombres" / "en nombre nuestro proprio"; "las casas suyas mayores" / "sian sacados de dentro de mjs casas". A pesar de lo que pueda parecer, el adjetivo propio (o proprio) no influye en la selección de una forma u otra, tal y como muestran la totalidad de los datos extraídos. Tampoco parece influir la cantidad de adjetivos que se coloquen delante o detrás del sustantivo, es decir, que la frase esté más cargada en la parte delantera o en la trasera, o que se trate de un sintagma nominal o preposicional. 
Podemos observar, asimismo, que, con el indefinido todo, la estructura que se favorece es siempre la antepuesta: "todos nuestros bienes assi mobles como sedientes"; "a todas vuestras proprias voluntades", "todas nuestras vozes", "todo nuestro dreyto" (pero, "bienes mjos mobles proprios quitos e desembargados"). Es decir, esta palabra parece condicionar, en cierta medida, el uso de la construcción que se ha denominado "no marcada". Del mismo modo, el adjetivo dito/a promueve la construcción artículo + posesivo átono + sustantivo; aunque, de hecho, más bien parece a la inversa: esta construcción solamente funciona si se incluye dito/a, por lo que la estructura propiamente dicha sería la siguiente: artículo + dito/a + posesivo átono + sustantivo. Solamente hay una excepción a esta norma: "de los ditos padre et madre suyos", o dos si tenemos en cuenta la variante sobredito/a: "por algunas de las sobreditas jndempnidades vuestras". Por su parte, aquellas expresiones que establecen relaciones de parentesco a través de una aposición requieren habitualmente del posesivo pospuesto: "et don Artal fillo suyo", "don Artal d'alagon mayor de días aguelo vuestro", "don Pedro d'Alagon marido nuestro".

Así, podemos ver que en ocasiones hay factores que influyen en la opción por una estructura posesivo $u$ otra; sin embargo, otras veces podemos observar la mezcla de diferentes expresiones en coordinación, lo que implica una gran libertad de uso: "et don Artal de alagon su fillo et padre vuestro", "en las casas de nuestras habitaciones e suyas".

\subsection{El Libro de los testamentos de Vicente Rodilla}

Los textos seleccionados del Libro de los testamentos del notario Vicente de Rodilla de Zaragoza constan de 276 estructuras posesivas, de las cuales:

- Posesivo átono + sustantivo son 115 casos (41,67\%): "mi ultimo testament", "de todos mis bienes mobles e sedientes", "de mis peccados", "todos mis tuertos, deudos e injurias", "en mi buen seso", "pora mi sepultura", "de su anima", "con sus candelas costumbradas", "de sus bienes e periglo de lures ${ }^{4}$ animas".

\footnotetext{
${ }^{4}$ Recordamos que lures es la forma propiamente aragonesa para el posesivo de 3. persona en plural; en singular, lur (< * ILLURUM). Por lo tanto, son equivalentes a su y sus, y así los hemos contabilizado como
} 
- (Artículo) + sustantivo + posesivo tónico son 128 casos (46,38\%): "por el present codicillo mio", "Maria Stevan de Quesadas, muller mia", "todos los ditos bienes mios mobles e sedientes", "al dito fillo mio", "de los otros bienes mios", "herederos mios universales.", "por procurador suyo", "contra los bienes nuestros", "e la cota mia de gamellin nueva", "cosa suya propia".

- Artículo + posesivo átono + sustantivo son 28 casos (10,14\%): "al dito su testament", "la dita mi muller", "de la dita mi sepultura", "por los ditos mis exequtores", "el present mi ultimo testament".

- Reduplicación del posesivo con genitivo son 5 casos (1,81\%): "todo el tiempo de su vida d'ella", "todo el tiempo de su vida d'el", "de sus bienes d'ellos".

Destacamos que, dentro de la construcción posesivo átono + sustantivo son 18 los ejemplos que llevan los determinantes esti / aquesti, es decir, un 6,52\% del total: "aquesti mi ultimo testament", "d'esti mi testament", "aquesti mi codicillo". Estos determinantes, sin embargo, no aparecen en otras expresiones posesivas. Además, en estas construcciones con determinante, a excepción de un solo caso, en el resto el objeto poseído siempre es el testament. Es probable que los determinantes seleccionen esta construcción y que, por otra parte, el sustantivo testament siempre prefiera el posesivo antepuesto, ya que lo encontramos con preferencia en esta construcción -tanto con los determinantes como sin ellos- y en artículo + posesivo + sustantivo; sin embargo, es inexistente cuando el posesivo va pospuesto. De hecho, en la mayor parte de ocasiones en las que se da esta fórmula, lo hace con los siguientes sustantivos: testament, sepultura y executores. Por otra parte, y como en los pergaminos del Fondo Sástago, la expresión de la posesión con artículo y posesivo antepuesto necesita de la presencia de dito/a, excepto en una sola ocasión ("el present mi ultimo testament"). Además, este sintagma, con la voz present, que parece tener un carácter deíctico, se asemeja a los mencionados casos con esti / aquesti ("aquesti mi ultimo testament"). No sucede lo mismo a la inversa, puesto que dito/a también puede aparecer en otras construcciones: "todos los ditos bienes mios mobles e sedientes", "al dito fillo mio", "la dita muller mia", "la qual dita sepultura mia", "la dita vinnya mia", "a los ditos filla e postumo mios", etc. 
Al igual que testament, voluntat, anima, salario y peccado también aparecen siempre con posesivos antepuestos: "por fazer end a su voluntat", "de mis peccados", "a su voluntat", "por su salario", "por mi anima". Quizá no se deba a una simple preferencia léxica, sino más bien a que la estructura posesivo + sustantivo sea usada en contexto más fijos, en construcciones que tiendan a mantenerse y que, por lo tanto, estén ofreciendo un valor cuantitativo alto, pero cualitativamente bajo. No obstante, también se aprecia cierta inmovilidad en los posesivos pospuestos en algunas ocasiones: "apres días mios", o, como en el Fondo Sástago, la posposición del posesivo en los nombres de las relaciones familiares en aposición: "Johan Ximenez Mamillo, marido mio", "Martin de Cavaldos, fillo mio". En este mismo sentido, los elementos relacionados con la vida agrícola, que se presentan, además, habitualmente con un artículo indefinido, suelen escoger el posesivo pospuesto: "hun malluelo mio", "una vinnya e campo mios contiguos francos e quitos", "con la sobredita vinnya mia".

Sin embargo, no es extraño encontrar palabras o sintagmas que funcionan perfectamente con cualquier tipo de construcción posesiva: "todo el tiempo de su vida" / "todo el tiempo de su vida d'el", "de todos e cada unos bienes mios mobles e sedientes" / "de todos mis bienes mobles e sedientes", "la qual dita sepultura mia" / "mi sepultura". Asimismo, es posible hallar coordinación de dos construcciones diferentes: "la dita mi sepultura e los tuertos, deudos e injurias mias", "todos los otros bienes mios romanientes sines dannyo de sus bienes e periglo de su anima", "por el dito marido mio e por mi de sus bienes d'ellos".

\subsection{Protocolos notariales de Bartolomé Roca}

En los protocolos del notario Bartolomé Roca y de otros notarios zaragozanos de mediados del siglo xV (1443 y 1477) se recogen 126 construcciones posesivas, de las cuales:

- Posesivo átono + sustantivo son 85 casos (67,46\%): "mi muller Anthona de Torres", "en mi palacio", "mi muller a su madre", "pora mi moca", "su padre", "con su senyoria", "de sus ropas", "Domingo Jayla, su procurador e cunyado", "de vuestro servicio", "sin 
vuestra licencia", "todos sus tuertos", "a nuestro senyor Dios", "Johan e Domingo, sus hermanos", "por sus herederos et sucesores", "todos vuestros mandamientos licitos et honestos".

- (Artículo) + sustantivo + posesivo tónico son 24 casos (19,04\%): "en casa mia", "de casa mia contra voluntat mia", "Marica, mosca mia", "por letra suya", "a messiones mias", "de todos los otros bienes suyos", "como notario vuestro", "Pedro de Segura, criado e fillado suyo".

- Artículo + posesivo átono + sustantivo son 18 casos (14,3\%): "la dicha mi casa", "de la muller del dito mi tio", "por el suso dito mi tio", "de los ditos sus fillos", "de los ditos sus padre e madre", "la su anima".

Se observa claramente un porcentaje mucho más alto de las soluciones posesivo átono + sustantivo frente a cualquier otra construcción; además, es importante destacar que desde un punto de vista cualitativo, estas soluciones también son más relevantes, puesto que varios de los ejemplos de posesivo tónico pospuesto corresponden a la fórmula, más o menos fija, referente a los nombres de relaciones de parentesco en aposición: "Bertholomeu Roca, marido suyo", "Barcelona, muller suya”, "Pero Carrillo, tio mio". No obstante, también hemos localizado estas relaciones de parentesco o familiares con otro tipo de expresiones de posesivo, algo que no es habitual en los bloques de manuscritos estudiados hasta ahora: "don Lop, su hermano", "Domingo Jayla, su procurador e cunyado", "mosen Johan, su padre", "Johan e Domingo, sus hermanos".

De nuevo, se advierte que la estructura artículo + posesivo átono + sustantivo solamente aparece si se interpone la palabra dito (o la variante fonética castellana dicho o sobredito), a excepción de un solo caso: "la mi anima". Por otra parte, este adjetivo no es exclusivo de esta construcción, sino que es susceptible de aparecer en otras: "a los ditos fillos suyos", si bien con mucha menor frecuencia.

Reparamos en que hay ciertas construcciones que siempre se hacen con el mismo patrón, así: como + notario / aprocurador vuestro -con posesivo pospuesto-, o la fórmula propia del lenguaje notarial que suele situarse al inicio de los protocolos "de mi cierta sciencia" -con anteposición del posesivo-. A pesar de que los ejemplos muestran que muchas de las cosas poseídas se repiten incansablemente en todos los ejemplos, ello no 
se debe a preferencias léxicas, sino al tema que se trata en estos protocolos, que suele ser el mismo a lo largo de todos ellos.

Cuando hay coordinación de elementos, estos pueden seleccionar cualquier forma de posesivo, tanto la antepuesta como la pospuesta: "Domingo Jayla, su procurador $e$ cunyado" / "Pedro de Segura, criado e fillado suyo". Incluso en la misma coordinación puede haber diversidad de construcciones: "se fue la dicha mi moça de casa mia contra voluntat mia e de mi muxer". En una única oración podemos hallar mezcladas las tres construcciones de posesivo más habituales en documentos aragoneses medievales.

\subsection{Protocolos de Joan de Morales}

El protocolo de Joan de Morales de Samper de Calanda (Teruel) de 1499-1500 contiene 46 formas posesivas, de las cuales:

- Posesivo átono + sustantivo son 26 casos (56,52\%): "a mj fija", "de todo mj dreyto", "buestra senyoria", "por nuestros treballos", "en buestra part tocan", "su consentimiento", "sus ropas".

- (Artículo) + sustantivo + posesivo tónico son 7 casos (15,21\%): "asi como aprocurador suyo", "Ysavel Galceran, muller suya", "vnna binya nuestra", "con tiera blanca mja", "ffijos vuestros".

- Artículo + posesivo átono + sustantivo son 13 casos (28,26\%): "a las ditas mjs fillas", "al dito mj marjdo", "el dito mj principal", "el dito mj padre", "el dito mj hermano".

Lo más destacable de estos protocolos es la escasez de posesivos entre sus páginas. Por otro lado, y a diferencia de lo visto en bloques anteriores, la construcción (artículo) + sustantivo + posesivo tónico tiene muy poca presencia; además, podemos observar que los ejemplos hallados responden, en su mayoría, a expresiones lingüísticas frecuentemente unidas al posesivo tónico pospuesto, como son las relaciones familiares ("Ysavel Galceran, muller suya"), los elementos de la vida agrícola con artículo indefinido ("vnna binya nuestra", "vnas cassas mjas") y el oficio de aprocurador ("asi como aprocurador suyo", "procurador mjo"). La preferencia, pues, por la anteposición es muy 
clara, teniendo en cuenta, además, que los casos de artículo + posesivo átono + sustantivo también superan en número al posesivo tónico pospuesto.

No obstante, en concordancia con los documentos anteriores, la fórmula artículo + posesivo átono + sustantivo solamente es viable si se inserta dentro de ella el adjetivo dito, y esta vez no hay ninguna excepción a esta norma.

\subsection{Protocolos de Salvador de Aguas}

En los protocolos del alcañizano Salvador de Aguas (1450-1453) hemos hallado un total de 84 formas posesivas, de las cuales:

- Posesivo átono + sustantivo son 62 casos (73,80\%): "en su poder", "de su cierta sciencia", "por su propia actorjdat", "su testament e vltima voluntat", "por sus treballos", "de sus cuerpos", "todas sus joyas a sus fillos", "de su hermana Ysabel", "sobre todos sus bienes mobles hi sitios", "mj tio el prior", "de su matrjmonjo", "portales con sus puertas".

- (Artículo) + sustantivo + posesivo tónico son 18 casos (21,43\%): "sobre vna vinya suya", "heredero suyo vniuersal", "Pedro Sanón, tio suyo", "no es culpa suya", "en vn tapiado suyo", "assi como a procurador de Marja de Ayusa, muller suya".

- Artículo + posesivo átono + sustantivo son 4 casos (4,76\%): "a los ditos mjs spondaleros", "al dito mj tio", "la dita su madre", "los sus treballos".

Al igual que en los documentos de Samper de Calanda, el porcentaje de posesivo átono + sustantivo es mucho mayor que el de posesivo tónico pospuesto; sin embargo, esta última construcción tiende a aparecer en aquellos pasajes de la redacción notarial que son más libres, es decir, que están menos constreñidos al formulismo notarial, mientras que el posesivo antepuesto sin artículo es recurrente en algunas expresiones que son habituales en estos protocolos notariales: "obligoron sus personas hi bienes", "dius obligación de sus bienes", "renuncioron su propio judge", "en su buen seso e memorja", "de su cierta sciencia". Ello no quiere decir que esta forma de expresar la posesión no aparezca en otros momentos de la redacción. Por otra parte, la construcción pospuesta se limita a hacerlo con los poseedores de 3. a persona, siendo inexistentes los

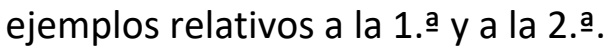


La construcción artículo + posesivo átono + sustantivo es ciertamente escasa y, de nuevo, está motivada por la aparición de dito, pues solamente hay un caso sin este adjetivo: "los sus treballos".

Aunque hemos hallado las habituales relaciones de parentesco en aposición con el posesivo pospuesto, también hemos advertido la presencia de estas con otro tipo de construcciones, por ejemplo, con el posesivo átono antepuesto: "e de Marja, su muller" o, mucho más habitualmente, con preposición de + pronombre personal / determinante, es decir, con una fórmula de genitivo simple: "hi Stranya, muller d'ell", "Cathalina, muller d'ell", "e a todos e qualesqujere bienes de aquella", "Los quales juroron em poder de mj, notario", "e darles comer, beuer, vestir e calçar condecentment segunt la condición d'ellos". Quizá esto se deba a la voluntad del notario por conseguir una redacción más latinizada, ya que es una continuación del uso latino el empleo del genitivo (fillium nostri). También es habitual encontrar en estos casos una frase de relativo que da cuenta de la posesión: “Dona Ysabel Fulla, muller que fue del honorable Anthon Piquer, [...] assi como detenedera, posseydera hi vsufructuarja de todos los bienes [...] que fueron del dito Anthon Piquer", "Clara Soler, muller que fue del dito Johan", "muller que fue mja". Es decir, observamos varios procedimientos para evitar el empleo directo de posesivos átonos o tónicos; advertimos que prefiere el uso de antropónimos, quizá para eludir la ambigüedad que resulta de los pronombres de 3. a persona. Esto influye directamente en el escaso número de estos a lo largo de todos los folios analizados de Salvador de Aguas.

\subsection{Documentos notariales de Teruel}

Los documentos notariales turolenses redactados entre 1420 y 1453 presentan 155 expresiones posesivas, de las cuales:

- Posesivo átono + sustantivo son 125 casos (80,64\%): “en mi buena leyal acomanda", "de mi cierta sciencia", "por todo lur poder", "lures fierros o señales", "con su márrega", "con sus carros \& ropas", "por mi anima", "obligo mi persona \& todos mis bienes", "a toda vuestra propia voluntat", "en vuestra compannia", "su mandamiento", "a 
sus vinyas", "de sus lanas", "de su fijo", "con nuestras manos derechas", "tu padre", "su bacineta".

- (Artículo) + sustantivo + posesivo tónico son 20 casos (12,90\%): “de todo el derecho nuestro et de la dita iglesia", "vna pieza de tierra mía", "Johana, casera mía", "a instancia suya", "con prouissión suya", "de ordenación e mandamiento vuestro fiz", "en poder mío", "bienes mobles míos propios", "huna masada suya", "a discreción suya".

- Artículo + posesivo átono + sustantivo son 8 casos (5,16\%): "en el dito su oficio", "en el dito su pago", "fijo del dito mi marido", "filla del dito mi marido \& mía", "del dito mi marido \& míos", "al dito su marido", "un su fillo".

- Artículo + posesivo tónico + sustantivo son 2 casos (1,29\%): “por los míos succesores presentes", "ayan poder de la suya senyoría".

La diferencia de porcentajes entre las dos formas predominantes es muy amplia. EI posesivo átono + sustantivo supera con creces, tanto cuantitativamente como cualitativamente, al posesivo tónico pospuesto. Aún con todo, el número total de construcciones de posesivo no es muy alto debido a que, como en los documentos alcañizanos, se opta en muchas ocasiones por el genitivo ("madre de mi", "amigos de nos") o este genitivo se emplea para especificar el poseedor ("Johaní que marquaba \& su hermano de Johani").

Ninguna de las dos construcciones favoritas parece estar motivada en ningún caso, aunque es cierto que hay sustantivos muy frecuentes con el posesivo átono; sin embargo, esto se debe a que son muchos más los ejemplos con esta expresión. De hecho, hay sustantivos susceptibles de aparecer en cualquier situación: "de lur poder", "en mi poder" / "en poder mio"; "todos sus bienes mobles" / "bienes mobles míos propios". Otras construcciones que en los textos analizados anteriormente parecían motivados, aquí se dan indistintamente: "Manuel Sánchez, su hermano" / "Johana, casera mía"; "a sus vinyas" / "huna masada suya".

No obstante, la motivación aquí parece estar más marcada por el gusto del notario, puesto que se advierten ciertas diferencias de empleo de estructuras de posesivo según el documento que se analice. De este modo, el documento n. 41 contiene una de las formas que parecen más propias del Alto Aragón ("por los míos succesores presentes") y un número elevado de estructuras con el posesivo tónico pospuesto; el n.o 85 presenta, 
asimismo, más casos de este tipo que el resto de documentos. En este mismo sentido, la forma aragonesa lur(es) también se halla constreñida casi en su totalidad a un documento, el n.o 33, donde aparecen 7 de los 10 casos totales que hemos registrado.

Como parece ya norma, la estructura artículo + posesivo átono + sustantivo está condicionada por la intromisión de dito, con una única excepción ("un su fillo"), que además tiene la peculiaridad de estar introducido por un artículo indefinido, artículo que no aparece en los casos que llevan el adjetivo dito. También es remarcable que cuando este adjetivo se incluye en la expresión de la posesión, lo hace bajo la fonética aragonesa -dito-, mientras que es bastante habitual que en otras ocasiones donde no se marca la posesión se recoja bajo su forma castellana dicho.

\section{Discusión}

Hemos podido comprobar que las dos construcciones de posesivo más frecuentes en los textos aragoneses analizados son posesivo átono + sustantivo y (artículo) + posesivo tónico + sustantivo, mientras que artículo + posesivo átono + sustantivo es ciertamente escasa. Ello muestra que la pugna sobre la que tanto se ha estudiado en castellano medieval y renacentista -sobre todo teniendo en cuenta la hipótesis de que esta última se trata de una fórmula "marcada", bien estilísticamente bien gramaticalmente, frente a una expresión "no marcada"-, no tiene vigencia en el territorio central y meridional aragonés en la medida en que la tienen las dos construcciones preferentes mencionadas. De los 6 documentos considerados, 2 muestran un porcentaje mayor del posesivo tónico pospuesto, mientras que los otros 4 prefieren la estructura con el posesivo átono antepuesto. Esto nos lleva a considerar que la balanza de la contienda se está decantando por la forma que también está triunfando por la misma época en castellano; sin embargo, esta expresión de la posesión todavía tiene vigencia en Aragón, si bien en unas regiones más que en otras.

Dicha variación de uso de ambas construcciones entre las distintas localidades estudiadas no parece tener una motivación determinada y clara; no obstante, quizá 
pueda relacionarse con un mayor mantenimiento del aragonés medieval. De esta suerte, son los testimonios de Sástago y del zaragozano Vicente de Rodilla los que muestran un mayor grado de conservación de este romance, seguidos por los del notario Salvador de Aguas, los de Bartolomé Roca y otros notarios zaragozanos y ya, por último, los de Samper de Calanda y los de Teruel. De igual modo sucede con el porcentaje referente a la construcción con posesivo tónico pospuesto. Un menor o mayor conservadurismo depende tanto de la región -pues los territorios más sureños, como Teruel, se castellanizaron antes- como de la fecha de redacción. Por ello, es lógico que los protocolos de Bartolomé Roca y los otros notarios zaragozanos presenten más características castellanas que los redactados en la misma localidad por Vicente Rodilla, puesto que fueron manuscritos con más de medio siglo de diferencia en un momento de rápido avance lingüístico castellano. Por otra parte, creemos que la diferencia de proporciones, asimismo, resulta de las propias características personales de los escribanos y de sus gustos personales. Por ejemplo, hemos advertido cómo algunos notarios de los documentos turolenses presentaban un mayor número de casos de posesivo tónico pospuesto frente a los otros.

Los dos documentos que presentan mayor proporción del posesivo pospuesto, además, exhiben un comportamiento de la estructura antepuesta mucho más constreñido y más limitado por la prosa notarial, lo que hace que los testimonios de las primeras construcciones sean más valiosos para determinar su empleo fuera de una constelación discursiva concreta. Algo similar sucede en los protocolos de Salvador de Aguas, pues, a pesar de un mayor volumen de posesivos antepuestos átonos, son los pospuestos tónicos los que aparecen en fragmentos de redacción más libre y más suelta. Así, podemos ver que hay ciertas estructuras del lenguaje notarial que optan, casi invariablemente por la anteposición: "apres días mios", "en mi buen seso e memoria", "(renunciar) mi judge", "como aprocurador vuestro / suyo /...", "mi / su cierta sciencia".

Pero, de igual modo, hemos advertido que otras expresiones ampliamente utilizadas en el registro notarial favorecen la aparición del posesivo pospuesto, como las relaciones de parentesco en aposición o los elementos relacionados con la vida agrícola. A pesar de que en algunos manuscritos las estructuras del tipo "Johan, marido mio" conviven con otras, estas son las que más difícilmente desaparecen de los textos 
aragoneses cuando priman las de posesivo átono + sustantivo, por lo tanto, podemos decir que se trata de una construcción altamente motivada. Por su parte, las estructuras como "una vinya mia" o "un campo suyo sitiado a..." tienen en común, no solamente el posesivo, sino también la aparición del artículo indefinido, que se manifiesta escasamente en otro tipo de expresiones posesivas. De esta suerte, podemos reparar en que este artículo se decanta por estructuras en las que no confluye con el posesivo en el mismo margen izquierdo del sintagma nominal.

Romero Cambrón ha prestado especial atención a la construcción (artículo) + posesivo tónico + sustantivo en algunos de sus últimos artículos. Ha observado que son altamente frecuentes en los Documentos Lingüísticos del Alto Aragón de Tomás Navarro Tomás (Romero Cambrón 2008: 76) y ha dictaminado que estas formas tienen su origen en tierras aragonesas (Romero Cambrón 2016: 15). Asimismo, ha analizado las causas por las que el posesivo se trasladó desde el margen izquierdo del sintagma nominal al margen derecho (Romero Cambrón 2016). ${ }^{5}$ Tras analizar los datos que aquí presentamos, respaldamos la hipótesis de esta investigadora en relación con su origen o mayor difusión por el territorio aragonés, hecho que ya fue advertido anteriormente por Umphrey (1987: 188), puesto que hemos observado que brotan con frecuencia en textos aragoneses, incluso del sur, y que estas construcciones pueden aumentar con el grado de mantenimiento del romance autóctono, lo que podría implicar una relación directa entre la lengua aragonesa y el uso de estos posesivos.

En relación con la estructura artículo + posesivo átono + sustantivo, ha quedado claro que no es una construcción muy habitual en el centro y mediodía aragonés del siglo XV. Aún con todo, podemos hacer ciertas observaciones sobre ella. En primer lugar, es manifiesto que la estructura de la que debemos hablar, en todo caso, es artículo + dito/a + posesivo átono + sustantivo, ya que aparece con este adjetivo en la mayor parte de ejemplos extraídos. Por lo tanto, es este adjetivo el que favorece esta estructura concreta. En segundo lugar, se presenta de manera más abundante en los documentos de Samper de Calanda, que son los más tardíos de todo el corpus. Esto puede llamar la

\footnotetext{
${ }^{5}$ Para ello, ha sido necesario indagar algo más sobre el origen de las formas tuyo y suyo. Para más información acerca de este tema, véase Romero Cambrón (2009), Menéndez Pidal (1999) y Penny (1993).
} 
atención en un principio, puesto que la mayor vitalidad de esta construcción es propia de un estado de lengua más antiguo. Estos datos concuerdan con los que recoge Albesa (2017: 42) en un acta notarial de 1624 en el Bajo Aragón turolense, donde también hay un número considerable de ejemplos de esta construcción, más todavía si tenemos en cuenta que dicho manuscrito fue redactado en la primera mitad del siglo XVII. Es posible que, tal y como enuncia Clavería (1992: 357), tras una época de pérdida, se haya producido un proceso de revalorización de esta fórmula en ámbitos notariales que quizá quieran dar a su redacción un resabio antiguo o culto. La fecha del repunte de esta construcción propuesta por esta investigadora es el siglo XV, pero quizá en Aragón se produjo más tardíamente o perduró más en el tiempo.

Además de las tres expresiones de posesivo que hemos comentado, hemos documentado otras dos, si bien con una aparición muy escasa: el doble posesivo con genitivo ("su vida d'ell") y la que se ha considerado prototípicamente aragonesa artículo + posesivo tónico + sustantivo ("e los mjos herederos"). La doble posesión se circunscribe al uso de un único notario y, además, a casi un único ámbito de actuación, la vida, por lo que podemos inferir que era una fórmula o bien desconocida o bien evitada por el resto de notarios. La segunda construcción ha sido hallada por Enguita \& Lagüéns (1992: 73) en el Ceremonial de consagración y coronación de los Reyes de Aragón y por Enguita (2009: 127) en algunos documentos del Alto Aragón, pero no en zaragozanos. Romero Cambrón afirma que "la construcción el suyo fillo estuvo adscrita a un ámbito geográfico concreto, el constituido por La Rioja y Aragón, donde debió estar bien arraigada en el periodo medieval" (Romero Cambrón 2014: 356). Gracias a estas consideraciones y a los datos que hemos extraído en esta investigación, pensamos que esta construcción fue más propia del aragonés del Alto Aragón que del aragonés central y meridional, donde esta variante parece que nunca gozó de mucho éxito. De este modo, esta es una característica más que puede diferenciar el aragonés empleado en los Pirineos en la Edad Media del que se extendió por los territorios situados más al sur durante la Reconquista. 


\section{Conclusiones}

A pesar de las tendencias generales que hemos advertido en la expresión de la posesión, parece claro que no existen, en los documentos seleccionados, unos patrones definitivos de uso de unas $u$ otras construcciones. Es decir, no hemos hallado obligatoriedad de uso ante ciertas motivaciones lingüísticas. Claro ejemplo de ello es la coordinación de diferentes estructuras posesivas, que implican cierta libertad en la selección de variantes. En algunas ocasiones, puede incluso tratarse de variantes invisibles, siguiendo la terminología de Barra Jover (2009a, 2009b), es decir de "la alternancia de formas, consideradas gramaticales en una época, para una misma función por parte de un mismo hablante, que utiliza una u otra de manera inconsciente y sin que medien un contexto o un contexto determinados", tal y como aplica Serradilla (2010: 55) al estudio de los posesivos en el Calila e Dimna.

Por otra parte, también hemos notado que no todos los testimonios empleados exhiben el mismo comportamiento lingüístico. Esto se debe a las ya mencionadas variaciones dentro del aragonés medieval. Aparte de las diferencias en las expresiones posesivas que ya hemos comentado, queremos mencionar, si bien de manera breve, el caso de lur. Este posesivo aragonés solamente lo hemos encontrado en los pergaminos del Fondo Sástago y en unos pocos documentos de Teruel y alrededores recogidos por Terrado (1991), hecho que resulta de interés puesto que esta forma se circunscribe a los valles pirenaicos en la Edad Media, ya que, por lo general, no llegó a las tierras meridionales con el proceso de nivelación (Pato 2015: 26). De esta suerte, podemos observar que la heterogeneidad lingüística es un factor que debemos tener en cuenta en cualquier estudio de corte diacrónico, máxime en aquellos que hacen referencia al aragonés medieval. 


\section{Corpus empleado}

ALBESA PEDROLA, Elena (en prensa) La lengua en el Bajo Aragón a través de documentación notarial (1450-1453). Transcripción y estudio lingüístico, Tesis doctoral de la Universidad de Zaragoza (15 diciembre de 2017).

Del CAMpo GutiérReZ, Ana (2011) El Libro de Testamentos de 1384-1407 del notario Vicente de Rodilla. Una introducción a los documentos medievales de últimas voluntades de Zaragoza, Zaragoza: Institución «Fernando el Católico».

Lleal GalCerÁn et al. (2007) Pergaminos aragoneses del Fondo Sástago: siglo XV, Zaragoza: Institución «Fernando el Católico».

LOZANO GRACIA, Susana (2012) La familia y el trabajo bajo la mirada de un notario de la Zaragoza del siglo XV. El libro de Bartolomé Roca (1454-1490), Zaragoza: Institución «Fernando el Católico».

PaRís MARQuÉs, Amparo (2016) El protocolo de Joan de Morales. Actuación de los notarios en Samper de Calanda (Teruel) hasta el siglo XVI, Zaragoza: Institución «Fernando el Católico». TeRRAdo PABlo, Javier (1991) La lengua de Teruel a fines de la Edad Media, Teruel: Instituto de Estudios Turolenses, Excma. Diputación Provincial de Teruel.

\section{Referencias bibliográficas}

AlbeSA Pedrola, Elena (2017) Concordia entre la villa de Alcañiz y los barrios de Valdealgorfa, Valjunquera y La Codoñera (1624). Edición y aproximación lingüística a este texto notarial del Bajo Aragón, Zaragoza: Institución «Fernando el Católico».

ALVAR LóPEZ, Manuel (1953) El dialecto aragonés, Madrid: Gredos.

BAdia Margarit, Antoni Maria (1950) El habla del valle de Bielsa (Pirineo aragonés), Barcelona: C.S.I.C.

BARRA JOVER, Mario (2009a) "Des variantes invisibles à la fragmentation des langues romanes", Recherches Linguistiques de Vincennes, 38, 107-132.

BARRA JOVER, Mario (2009b) “Las 'variantes invisibles'. El ejemplo de la evolución de las subordinadas y otros casos relacionados», Cahiers d'Études Hispaniques Médiévales. Número monográfico: La transformación del castellano medieval: sistema, formas de transmisión y entorno social, 32, 17-32. 
Dialectologia 25 (2020), 1-24.

ISSN: 2013-2247

CLAVERía NADAL, Gloria (1992) "La construcción artículo + posesivo en los siglos XIV y XV", en Manuel Ariza Viguera (ed.), Actas del II Congreso Internacional de Historia de la Lengua Española (Sevilla, 1990), vol. I, Madrid: Arco Libros, 347-358.

COMPANY COMPANY, Concepción (2001) “Gramaticalización, debilitamiento semántico y reanálisis. El posesivo como artículo en la evolución sintáctica del español", Revista de Filología Hispánica, LXXXI, 1 / 2, 49-87.

Company Company, Concepción (2006) “Persistencia referencial, accesibilidad y tópico: la semántica de la construcción artículo + posesivo + sustantivo en el español medieval", Revista de Filología Española, 86 (1), 65-103.

COMPANy COMPANy, Concepción (2009) "Artículo + posesivo + sustantivo y estructuras afines", en Concepción Company Company (dir.), Sintaxis histórica de la lengua española. Segunda parte: La frase nominal, vol. II, México: Fondo de Cultura Económica y Universidad Nacional Autónoma de México, 759-880.

EBEREZ, Rolf (2000) El español en el otoño de la Edad Media. Sobre el artículo y los pronombres, Madrid: Gredos.

EGIDO FERNÁNDEZ, M. a Cristina (1999) “Artículo + posesivo + sustantivo en documentación leonesa del siglo XIII", en José Enrique Martínez Fernández (coord.), Trilcedumbre (Homenaje al profesor Francisco Martínez García), León: Universidad de León, 157-169.

ENGUITA UTRILLA, José María (2009) "Variedades internas del aragonés medieval", en Vicente Lagüéns Gracia (ed.), Baxar para subir. Colectánea de estudios en memoria de Tomás Buesa Oliver, Zaragoza: Institución «Fernando el Católico», 111-149.

Enguita Utrilla, José María \& Vicente Lagüéns Gracia (1992) “Aspectos lingüísticos", en Ceremonial de consagración y coronación de los Reyes de Aragón, Zaragoza: Centro de Documentación Bibliográfica Aragonesa de la Diputación General de Aragón, vol. II, 57-84.

SEIBANE Gómez, Sara (2010) “De nuevo sobre artículo + posesivo + sustantivo. Textos vizcaínos de los siglos XV-XVIII", Nueva Revista de Filología Hispánica, 58 (1), 241-256.

HAENSCH, Günther (1961-1962) "Las Hablas de la Alta Ribagorza (Pirineo Aragonés)", Archivo de Filología Aragonesa, XII-XIII, 117-250 [reed. en (2003): Las hablas de la Alta Ribagorza, Zaragoza, Gara d’Edizions, Institución «Fernando el Católico»].

KUHN, Alwin (2008 [1935]) El dialecto aragonés. Trad. de José Antonio Saura y Xavier Frías, Zaragoza: Prensas Universitarias de Zaragoza, Xórdica Editorial. 
Lapesa Melgar, Rafael (2000) "Sobre el artículo ante posesivo en castellano antiguo", en Rafael Cano Aguilar y M.a Teresa Echenique Elizondo (eds.), Estudios de morfosintaxis histórica del español, Madrid: Gredos, vol. I, 413-435.

MENÉNDEZ PIDAL, Ramón (1999) Manual de gramática histórica española, [1.a ed. 1904], Madrid: Espasa.

PATo Maldonado, Enrique (2010) "Algo más sobre la historia del posesivo lur", Archivo de Filología Aragonesa, LXVI, 13-32,

Pato Maldonado, Enrique (2015) “El posesivo (antepuesto) tónico en español: ¿fenómeno de foco y contraste?", Dialectologia, 14, 47-73.

<http://www.publicacions.ub.edu/revistes/dialectologia14/>

PENNY, Ralph (1993) Gramática histórica del español, Barcelona: Ariel.

PÉREZ SALDANYA, Manuel (2009) "Si per la tua gràcia podia eu conservar ma vida 'if by your grace i could preserve my life': prenominal possessive constructions in old catalan", en Rafael Cufí (ed.), Diachronic Linguistics, Gerona: Documenta Universitaria, 275-298.

RodríGUez BARReIRO, Ana (2003) “La sintaxis del posesivo en castellano medieval: una construcción característica", Res Diachronicae, 2, 284-293.

ROMERO CAMBRón, Ángeles (2008) "Los posesivos en la historia del español: estimaciones críticas», Círculo de Lingüística Aplicada a la Comunicación, 35, 62-83.

Romero Cambrón, Ángeles (2009) "Sobre el origen de los posesivos tuyo y suyo», Cahiers d'études hispaniques médiévales, 32, 83-100.

Romero CAMBrón, Ángeles (2014) "Los posesivos en la producción herediana (ensayo de panorámica general sobre el aragonés)", Zeitschrift fur romanische philologie, 130, 2, 352369.

ROMERo CAMBRón, Ángeles (2016) “La expansión del posesivo pospuesto a la luz de documentación navarra (y aragonesa) del siglo XIII", Scripta. Revista internacional de literatura i cultura medieval i moderna, 7, 1-20.

SerRAdilla CAStillo, Ana (2003) “¿Existe la originalidad en sintaxis? El caso de la 'desaparición’ de la construcción 'artículo + posesivo' en español", Pandora: revue d'études hispaniques, 3, 257-272.

SeRRADILla CASTILlo, Ana (2010) "Artículo + posesivo + nombre frente a posesivo + nombre como variante invisible en un texto medieval", Epos. Revista de filología, 26, 53-76.

UMPHREY, George Wallace (1987 [1907]) “El dialecto aragonés” [Trad. de Manuel Alvar Ezquerra], Archivo de Filología Aragonesa, XXXIX, 163-201. 